\title{
Canada to specialize in aging research
}

With help from an economic development fund run by the Canadian government, a new research facility, the Centre of Health Research for the Elderly, will be opened soon at the St. Boniface General Hospital Research Centre (SBGHRC) in Winnipeg, Manitoba. The federal and provincial governments will each contribute CAN\$2.1 million (US\$1.42 million) to the center and the remaining $\$ 8.4$ million of the construction and start-up costs is being raised from private donations. The first group of scientists recruited to the facility will move into the newly constructed laboratories in August, and officials at the SBGHRC hope to finish staffing the center some time next year.

The focus of the new labs will be on studies related to senile dementia and cardiovascular disease, areas which many experts predict will be increasingly important as the average age of the world population rises. As the World Health Organization's 1998 World Health Report predicts, "in the 21st century, postponing the adverse effects of old age for as long as possible will be a major political and personal preoccupation."

Although the political motivation for the new center arose from the government's desire to boost jobs and economic development in Canada's western provinces, Harry Schulz, business manager for the SBGHRC, claims that Winnipeg is an inherently good location for a facility of this type:

\section{IMAGE UNAVAILABLE FOR COPYRIGHT REASONS}

"Everybody talks about the aging population, but in fact in Manitoba, by the turn of the century, we will have the oldest population in the country."

Once construction is completed, the province will also have the country's largest center for studying aging. "I would say that the center that we're building ... will be larger than anything else in the country . We're really trying to establish a critical mass here of people dedicated [to research on aging]," explains Schulz. In addition to the center, SBGHRC plans to set up a memory disorder clinic in a nearby personal care home for the elderly.
When asked if it would be difficult to recruit scientists to move to Winnipeg, Schulz replied: "I know where you're going with this-we're not the Mayo Clinic," referring to the famous, but remote biomedical research center in Minnesota, US. Officials at the SBGHRC hope that the research already being done there and the opportunity to work in a new facility will attract researchers early in their careers. "We aren't going to be looking for people who are at the top of the hill and looking down, but we're going to be seeking out exceptional young people," explains Schulz.

Alan Dove, New York

\section{Will increased surveillance help asthma research?}

Major players in the US health establishment are focusing attention on asthma to discover why the number of people with the disease has more than doubled in the past two decades. New data from a retrospective study carried out by the Centers for Disease Control and Prevention (CDC), shows that the number of asthma cases has increased from 6.8 million to 15 million since 1980 , and that incidence has risen particularly in urban areas. Asthma afflicts 150 million people worldwide.

In one effort to deal with the problem, Health and Human Services (HHS) Secretary, Donna Shalala, announced in May the release of an extra $\$ 2.5$ million research dollars per year for the next five years to the National Heart Lung, and Blood Institute. The money will be used to study the effect that infectious diseases such as respiratory syncitial virus (thought to be the cause of around one third of asthma cases) have on predisposing children to the disease. The funds are part of an overall $\$ 100$ million asthma effort by the HHS targeted at basic research, medication evaluation, environmental studies, education and prevention.

In addition to increased funding, there is a growing effort to set up a 'national public health surveillance' system to facilitate reporting of the disease in terms of its frequency and location across America. Information about asthma is currently gathered on a sporadic basis through a variety of methods.

On June 14th, the Council of State and Territorial Epidemiologists-an independent association that advises the CDC on which diseases should be regularly monitored-voted to recommend that asthma be placed under a national surveillance system that will require data to be collected regularly through mortality and morbidity num- bers from every state and territory.

President of the Children's Health Fund of New York City, Irwin Redlener, believes that intensifying surveillance will lead to better understanding of the cause of asthma. "There are a lot of epidemiologicdemographic issues surrounding asthma that may help open new lines of inquiry for basic research as well as prevention, " says Redlener.

However, the funding and manpower required to monitor asthma on such a large scale is known to have been a prime concern of the CDC when the issue has been raised in the past. CDC's Stephen Redd does not agree that national surveillance will lead to quicker solutions. "I don't think having a disease under surveillance really means very much. It's really how the information is used as part of an overall program of research and intervention that counts."

MARTIN KOHL, NeW YorK 